\title{
Laboratory biosafety measures involving SARS-CoV-2 and the classification as a Risk Group 3 biological agent
}

\author{
Alexa M. Kaufer ${ }^{1}$, Torsten Theis ${ }^{1}$, Katherine A. Lau ${ }^{1}$, Joanna L. Gray ${ }^{1}$, \\ WILLIAM D. RAWLINSON ${ }^{2}$ \\ ${ }^{1}$ Royal College of Pathologists of Australasia Quality Assurance Programs, Biosecurity \\ Department, Sydney, NSW, Australia; ${ }^{2}$ Serology and Virology Division (SAViD), NSW Health \\ Pathology, SOMS and BABS, University of New South Wales, Sydney, NSW, Australia
}

\begin{abstract}
Summary
The current public health emergency surrounding the COVID-19 pandemic, that is the illness caused by severe acute respiratory syndrome coronavirus 2 (SARS-CoV2 ), has resulted in thousands of cases in Australia since 25 January 2020 when the first case was diagnosed. This emerging virus presents particular hazards to researchers and laboratory staff in a clinical setting, highlighted by rapid and widespread global transmission. Based on the epidemiological and clinical data that have become available in mid-2020, we propose the interim classification of SARS-CoV-2 as a Risk Group 3 organism is reasonable, and discuss establishing Biosafety Level 3 (BSL-3) regulations accordingly. Despite its global spread, the reported mortality rate of SARS-CoV-2 ranging from $0.13 \%$ to $6.22 \%$ is considerably less than that of other Risk Group 4 agents including Ebola and Marburg viruses with fatality rates as high as $90 \%$. In addition, studies have demonstrated that approximately $86 \%$ of patients presenting with severe courses of the disease are aged 70 years or above, with the presence of comorbid conditions such as cardiovascular and respiratory system diseases in the majority of all fatal cases. In contrary to recent discussions surrounding the protective and administrative measures needed in a laboratory, the emerging evidence surrounding mortality rate, distinct demographics of severe infections, and the presence of underlying diseases does not justify the categorisation of SARS-CoV-2 as a Risk Group 4 organism. This article summarises biosafety precautions, control measures and appropriate physical containment facilities required to minimise the risk of laboratory-acquired infections with SARS-CoV-2.
\end{abstract}

Key words: SARS-CoV-2; COVID-19; SARS-CoV; biosafety level; physica containment; risk group.

Received 28 August, revised 20 September, accepted 21 September 2020 Available online 30 September 2020

\section{INTRODUCTION}

The transmission of novel infections amongst the general community poses a serious concern to public health. Upon an outbreak, it is essential to identify the causative agent in order to understand characteristics of the emerging pathogen such as those at risk of serious disease, transmission pathways, pathogenesis of disease, and host pathology. ${ }^{1}$ Given the novelty of the outbreak of COVID-19, the illness caused by severe acute respiratory syndrome coronavirus 2 (SARS-CoV-2), and the rapid spread of disease, significant biosafety considerations for healthcare and laboratory personnel exist. ${ }^{2}$ Appropriate biosafety measures and practices for the safe handling of the organism based on the assessment of potential hazards of SARS-CoV-2 must be established with high priority. ${ }^{1,3}$ The evolution of these guidelines will lay the groundwork for developing the best code of practice regarding microbiological practices, equipment, biosafety levels (BSL) and physical containment (PC) facilities required in Australian laboratories. The aim of this paper is to establish a set of guidelines and regulations based on international recommendations for Australian laboratories working with SARS-CoV-2 to minimise the risk of contracting COVID-19 whilst working in clinical laboratories.

\section{THE CORONAVIRIDAE FAMILY}

Viruses belonging to the Coronaviridae family are characterised by large, enveloped, single-stranded RNA with genomes ranging from 25 to $35 \mathrm{~kb}$ in size. ${ }^{4}$ Primarily causing mild respiratory or enteric infections in mammals, there are seven coronavirus species known to cause disease in humans including, MERS-CoV, SARS-CoV, SARS-CoV-2, HCoV NL63, HCoV 229E, HCoV OC43 and HCoV HKU1. Whole-genome analyses revealed an $82 \%$ similarity between SARS-CoV and SARS-CoV-2, with both genomes revealing a high degree of similarity to other SARS-like coronaviruses isolated from bats, which is suggestive of a common origin.

However, despite the genetic similarities, the trajectories and extent of community transmission of the viruses are vastly different. ${ }^{7}$ The SARS epidemic in 2003 resulted in approximately 8000 cases with over 700 deaths and was considered under control within 8 months. ${ }^{8}$ The SARS illness was first reported in China, and later spread to more than two dozen countries including, Singapore, Taiwan, Canada and the United States. In contrast, the unprecedented rate of COVID-19 compelled the World Health Organization (WHO) to classify SARS-CoV-2 as a global pandemic within 4 months of the initial outbreak. 


\section{LABORATORY BIOSAFETY: WORKING WITH MICROBIAL PATHOGENS}

Stringent guidelines with appropriate facilities, practices and protective equipment for the safe handling of SARSCoV-2 is vital to avoid laboratory-related infections and the spread of disease to those in close contact. The WHO suggests that countries (regions) should establish Risk Groups according to the microbes encountered within its borders. ${ }^{9}$ Various guidelines and standards have been established for countries including Australia, New Zealand, USA, Canada, and the European Union, where in most cases the information and grouping of biological agents are the same:

- Australian and New Zealand Standards AS/NZS2243.3: Safety in Laboratories Part 3: Microbiological safety and containment; ${ }^{10}$

- American Biological Safety Association webpage listings of microorganisms including risk groupings;
- PHAC (Public Health Agency of Canada) Pathogen Safety Data Sheets and Risk Assessments ${ }^{12}$; and

- Directive 2000/54/EC of the European Parliament. ${ }^{13}$

In general, microorganisms are categorised into four Risk Groups, based upon (i) the pathogenicity of the agent; (ii) the mode and ease of transmission; (iii) host range of the organism; and (iv) the local availability of effective preventative measures and treatment (Table 1). ${ }^{9}$ The Risk Group of an organism is categorised into four ascending levels of Biosafety Levels (BSL) BSL-1, BSL-2, BSL-3 or BSL-4 and Physical Containment (PC-1-PC-4) levels that are used to define the protective measures and physical structures required in a laboratory environment to protect workers and prevent the release of pathogens into the environment (Table 2). ${ }^{9}$ Similarly to Risk Group classification, the main criteria used to distinguish between the ascending levels of containment and Biosafety Levels 1 through 4, are infectivity, transmissibility, disease severity, and the type of work being conducted. ${ }^{14}$ All of these levels must correspond to the

Table 1 Risk Group classifications of biological agents

\begin{tabular}{|c|c|c|c|c|}
\hline & Risk group 1 & Risk group 2 & Risk group 3 & Risk group 4 \\
\hline \multirow[t]{2}{*}{ Description } & $\begin{array}{l}\text { Low individual and } \\
\text { community risk }\end{array}$ & $\begin{array}{l}\text { Moderate individual risk, } \\
\text { limited community risk }\end{array}$ & $\begin{array}{l}\text { High individual risk, limited community } \\
\text { risk }\end{array}$ & $\begin{array}{l}\text { High individual and } \\
\text { community risk }\end{array}$ \\
\hline & $\begin{array}{l}\text { Organisms that are already } \\
\text { present in the environment, } \\
\text { and are unlikely to cause } \\
\text { disease in a healthy host }\end{array}$ & $\begin{array}{l}\text { Organisms that can cause } \\
\text { disease in a healthy host but } \\
\text { are difficult to transmit, } \\
\text { don't usually cause life- } \\
\text { threatening illness and are } \\
\text { readily treated or prevented }\end{array}$ & $\begin{array}{l}\text { Organisms that usually cause disease in a } \\
\text { healthy host and may present a serious } \\
\text { risk to laboratory staff. RG-3 organisms } \\
\text { could present a significant community } \\
\text { risk if spread in the environment, but } \\
\text { there are usually effective measures for } \\
\text { treatment and/or prevention }\end{array}$ & $\begin{array}{l}\text { Organisms that cause life- } \\
\text { threatening disease in a } \\
\text { healthy host and } \\
\text { represents a serious } \\
\text { hazard to laboratory } \\
\text { staff. RG-4 organisms } \\
\text { are readily } \\
\text { transmissible, and } \\
\text { effective prevention } \\
\text { and/or treatment are not } \\
\text { usually available }\end{array}$ \\
\hline \multicolumn{5}{|l|}{ Sample organism } \\
\hline \multirow[t]{8}{*}{ Bacteria } & Escherichia coli & Bordetella pertussis & Bacillus anthracis & \\
\hline & Asporogenic Bacillus subtilis & Chlamydia spp. & Bartonella bacilliformis & \\
\hline & & Klebsiella spp. & Brucella spp. & \\
\hline & & Legionella spp. & Chlamydia psittaci & \\
\hline & & Salmonella enterica serovars & Coxiella burnetii & \\
\hline & & Salmonella Paratyphi A and B & Francisella tularensis (Type A) & \\
\hline & & Salmonella Typhi & Mycobacterium tuberculosis complex & \\
\hline & & Vibrio cholerae & $\begin{array}{l}\text { Rickettsia } \text { spp. } \\
\text { Yersinia pestis }\end{array}$ & \\
\hline \multirow[t]{12}{*}{ Viruses } & Adeno-associated virus & Adenovirus & Rift Valley fever virus (Zinga virus) & Guanarito \\
\hline & & Hepatitis A, B, C, E & SARS coronavirus & Junin \\
\hline & & Influenza & MERS - related coronavirus & Lassa \\
\hline & & Dengue $1,2,3,4$ & Japanese encephalitis & Machupo \\
\hline & & Zika & St Louis encephalitis & Mopeia viruses \\
\hline & & Measles & Tick-borne viruses & Sabia \\
\hline & & Menangle & West Nile & $\begin{array}{l}\text { Crimean-Congo } \\
\text { haemorrhagic fever }\end{array}$ \\
\hline & & Mumps & Yellow fever & Hazara \\
\hline & & Enterovirus & & Ebola \\
\hline & & & & Marburg \\
\hline & & & & Kyasanur Forest disease \\
\hline & & & & Tick-borne encephalitis \\
\hline $\begin{array}{l}\text { Biosafety Level } \\
\text { (BSL) }\end{array}$ & BSL-1 & BSL-2 & BSL-3 & BSL-4 \\
\hline $\begin{array}{l}\text { Physical } \\
\text { Containment } \\
\text { (PC) Level }\end{array}$ & PC-1 & PC-2 & PC-3 & PC-4 \\
\hline
\end{tabular}


Table 2 Description of Biosafety Levels (BSL) and Physical Containment (PC) facility requirements ${ }^{14,26}$

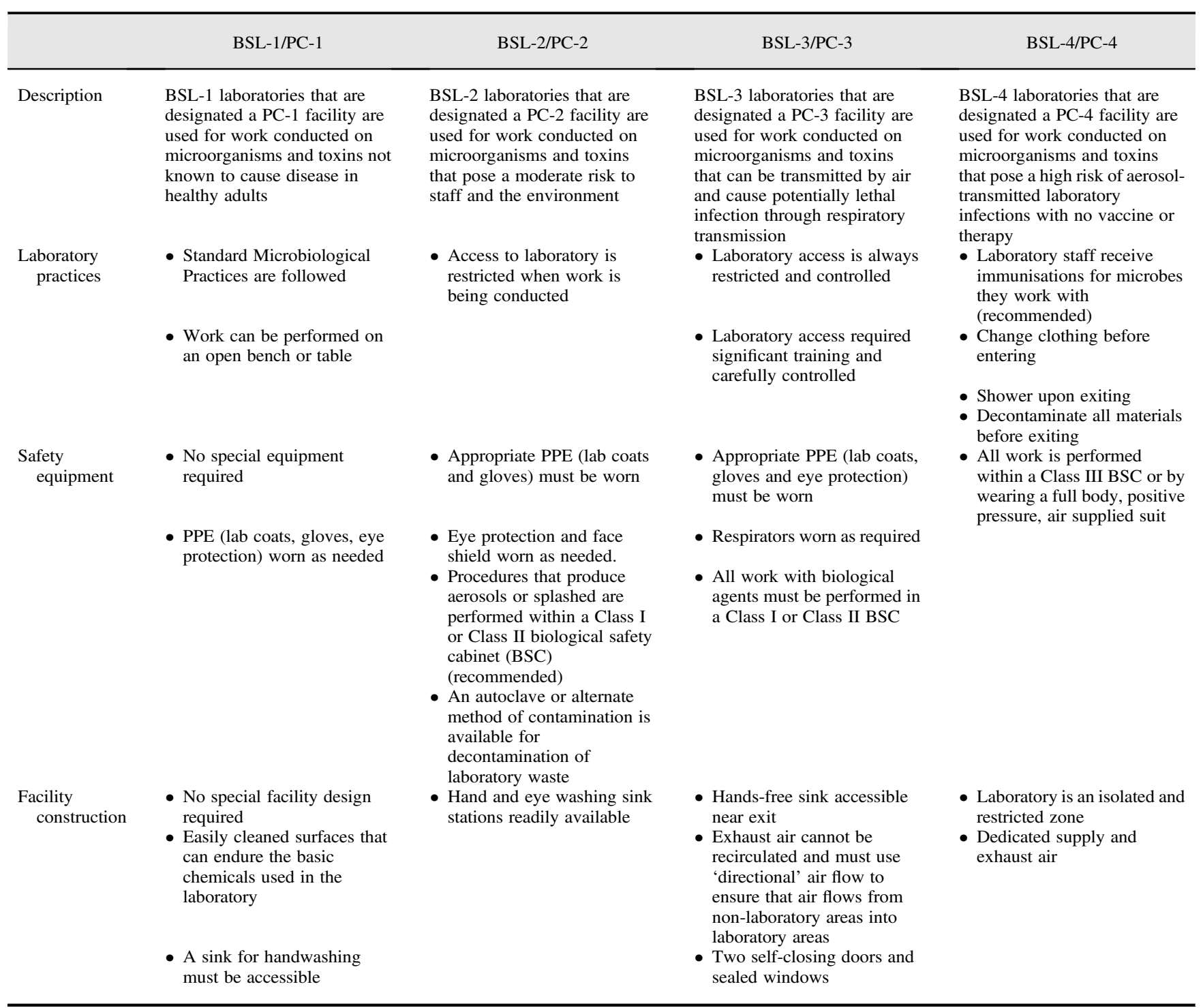

hazard and risk posed by the biological agent and the type of laboratory activity required. ${ }^{9}$ For example, the Risk Group of an organism should help determine the Biosafety Level that is required for the safe handling of the agent, and identify the appropriate physical containment facilities that should be used (Fig. 1).

To date, there has been no case of laboratory acquired infection of SARS-CoV-2 reported in the scientific literature. However, lessons learned from previous outbreaks have included the importance of quickly establishing and distributing laboratory guidelines for laboratory personnel safety. ${ }^{15}$ In 2003, the first case of the laboratory acquired SARS-CoV infection was reported in a laboratory setting after the initial global outbreak ended. ${ }^{16}$ Epidemiological investigations revealed the patient acquired the infection in his laboratory, with sequence analysis of the isolated strain matching laboratory samples of SARS-CoV with which he had been working 3 days prior to the onset of symptoms. ${ }^{16}$ The aetiology of SARS-CoV and SARS-CoV-2 share striking similarities, with recent evidence showing the transmission pathway of both viruses likely to be respiratory droplets, and the progression of disease following a similar pattern in patients. $^{7}$ Thus, laboratory-acquired infection with SARS-CoV2 is plausible if laboratory guidelines and safety precautions are not adhered to and concern regarding the potential risk to laboratory staff is justified.

\section{RISK GROUP CLASSIFICATION OF SARS- COV-2}

Interim recommendations published by the Centers for Disease Control (CDC) and WHO classified SARS-CoV-2 as a Risk Group 3 biological agent (Table 3). Contrary to this provisional assignment, it can be argued that SARS-CoV-2 is comparable to Risk Group 4 pathogens due to the rapid and worldwide spread of the virus, and the fact there is currently no effective antiviral treatment or protective vaccine available. ${ }^{17}$ Despite these recent discussions, ${ }^{17}$ the scientific data that have emerged show that the classification of SARS-CoV-2 as a Risk Group 4 organism is not justified according to the criteria defined in the Australian Standard AS/NZS2243.3 (Table 1). ${ }^{10,17}$ The closely related coronaviruses SARS-CoV 


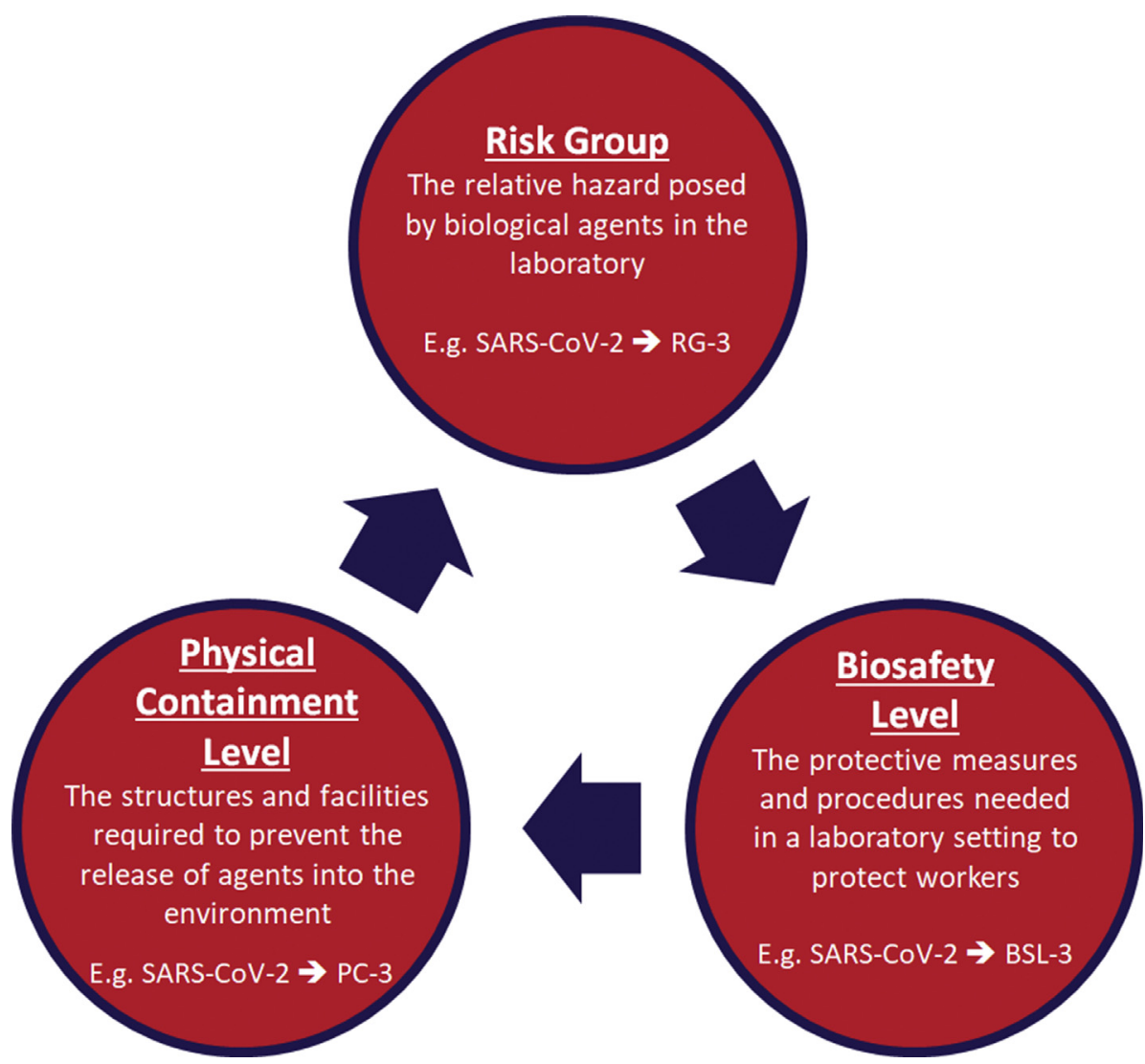

Fig. 1 Chart demonstrating how the Risk Group of an organism should help determine the biosafety level that is required for the safe handling of the agent, and identify the physical containment facilities that should be used.

Table 3 Classification of SARS-CoV and SARS-CoV-2 by the Australian Government Department of Health, Centers for Disease Control (CDC) and World Health Organization (WHO)

\begin{tabular}{|c|c|c|c|}
\hline & Australian Government Department of Health & $\mathrm{CDC}$ & WHO \\
\hline \multicolumn{4}{|l|}{ SARS-CoV-2 } \\
\hline $\begin{array}{l}\text { Non-propagative diagnostic laboratory work } \\
\quad \text { (routine diagnostic testing, sequencing, NAAT) }\end{array}$ & BSL-2 & BSL-2 & BSL-2 \\
\hline Propagative work (virus culture, neutralisation assays) & PC-3 & BSL-3 & BSL-3 \\
\hline \multicolumn{4}{|l|}{ SARS-CoV } \\
\hline Non-propagative diagnostic laboratory work (sequencing, NAAT) & BSL-2 & BSL-2 & BSL-2 \\
\hline Propagative work (virus culture, neutralisation assays) & BSL-3 & BSL-3 & BSL-3 \\
\hline
\end{tabular}

NAAT, nucleic acid amplification tests.

and MERS-CoV are classified as Risk Group 3 pathogens, even in the absence of effective treatments and vaccines. ${ }^{17}$ In addition, Risk Group 4 organisms are biological agents that are likely to cause severe or lethal disease in almost all infected individuals and are associated with high fatality rates of $>30 \%$. ${ }^{9,18}$ Viral haemorrhagic fevers (such as Ebola, Marburg, Lassa and Machupo viruses) represent one group of diseases that meet the Risk Group 4 criteria, characterised by severe febrile illnesses, widespread internal bleeding in tissues and organs, and high mortality rates (with reported death rates up to $90 \%$ with Ebola and Marburg virus outbreaks). ${ }^{19,20}$

The fatality rate of SARS-CoV-2 is considerably less than that of the criteria specified for Risk Group 4 organisms, with one study revealing a case fatality rate ranging from $0.13 \%$ to
$6.22 \%$ in a cross-country comparison. ${ }^{21}$ In addition, age and comorbidities have been identified as major risk factors in COVID-19 patients who develop a severe course of infection compared to those who are considered non-severe or asymptomatic. $^{22}$ Studies have demonstrated that fatal cases are predominantly in patients aged 70 years or above $(86 \%)$, with almost all deceased individuals suffering from underlying conditions including cardiovascular disease, diabetes and respiratory system disease. ${ }^{18,22}$ Asymptomatic patients appear to account for approximately $40-45 \%$ of all SARSCoV-2 infections, with the majority of infected people developing only mild illness that does not require hospitalisation. $^{23}$ Thus, unlike viral haemorrhagic fevers, SARSCoV-2 is not likely to cause severe disease in all infected 
patients as specified in AS/NZS2243.3, with only particular groups of individuals more likely to develop life-threatening respiratory infections.

We believe the data presented and provisional classification published by the WHO, CDC and various international governments, including the Australian Government Department of Health, justifies the assignment of SARS-CoV-2 as a Risk Group 3 biological agent. In addition, a risk assessment performed by the Australian Department of Health in conjunction with experts from the health, agriculture, gene technology and Australian intelligence sectors has determined that SARS-CoV-2 should not be included on the list of Security Sensitive Biological Agents. ${ }^{24}$ As more epidemiological and clinical information becomes available, it is evident that the data do not warrant a Risk Group 4 classification for SARS-CoV-2.

\section{RECOMMENDATIONS}

Given the evidence summarised in this article, the following guidelines are based on the assignment of SARS-CoV-2 as a Risk Group 3 biological agent. Laboratories must adhere to national guidelines on laboratory safety procedures, and ensure the handling of all suspected SARS-CoV-2 specimens is performed in strict observance of the relevant Biosafety Level.

Non-propagative routine diagnostic testing of specimens from patients who are suspected or confirmed COVID-19 positive can be conducted in a PC-2 laboratory using BSL2 practices. In addition, the Australian Public Health Laboratory Network (PHLN) recommends all manipulations of potentially infectious materials that may generate aerosols, droplets or splashes (including the loading and unloading of centrifuges, and vortexing) to be undertaken in PC-2 facilities using a Class II Biosafety cabinet. ${ }^{25}$ Examples of nonpropagative routine procedures include the use of automated platforms, sample processing, analysis of inactivated specimens, sequencing and nucleic acid amplification tests. Following standard precautions when handling material likely to be infectious, BSL-2 personal protective equipment (PPE) standard laboratory gowns, gloves, and face and eye protection are recommended for routine diagnostics.

Propagative work on SARS-CoV-2 or handling of material with high concentrations of live virus should only be conducted in a PC-3 laboratory using BSL-3 practices. Biosafety Level 3 practices include all BSL- 2 guidelines, with the addition of respiratory protection (such as N95/P2 masks) as required, and controlled access and decontamination of laboratory PPE before washing. Examples of propagative procedures include culturing of virus, isolation and neutralisation assays.

\section{CONCLUSION}

The risk assessment of novel pathogens is essential in public health to develop policies, regulations and control measures to protect scientists and healthcare professionals in the laboratory. All recommendations published by international and national health agencies (including the WHO and CDC), have assigned SARS-CoV-2 as a Risk Group 3 organism. We believe the interim classification of SARS-CoV-2 should be accepted and finalised to inform the appropriate biosafety levels, physical containment facilities and PPE required for the handling of SARS-CoV-2 and to minimise the risk of laboratory-acquired COVID-19 infections during this public health emergency.

Conflicts of interest and sources of funding: The authors state that there are no conflicts of interest to disclose.

Address for correspondence: Dr Alexa Kaufer, Suite 201, Level 2, 8 Herbert St, St Leonards, NSW 2065, Australia. E-mail: alexa.kaufer@ repaqap.com.au

\section{References}

1. Caly L, Druce J, Roberts J, et al. Isolation and rapid sharing of the 2019 novel coronavirus (SARS-CoV-2) from the first patient diagnosed with COVID-19 in Australia. Med J Aust 2020; 212: 459-62.

2. Lippi G, Adeli K, Ferrari M, et al. Biosafety measures for preventing infection from COVID-19 in clinical laboratories: IFCC Taskforce Recommendations. Clin Chem Lab Med 2020; 58: 1053-62.

3. Gorbalenya AE, Baker SC, Baric RS, et al. The species severe acute respiratory syndrome-related coronavirus: classifying 2019-nCoV and naming it SARS-CoV-2. Nat Microbiol 2020; 5: 536-44.

4. Payne S. Family Coronaviridae. In: Payne S, editor. Viruses. Cambridge: Academic Press, 2017; 149-58.

5. Hasöksüz M, Kiliç S, Saraç F. Coronaviruses and SARS-COV-2. Turk J Med Sci 2020; 50: 549-56.

6. Chan JF-W, Kok K-H, Zhu Z, et al. Genomic characterization of the 2019 novel human-pathogenic coronavirus isolated from a patient with atypical pneumonia after visiting Wuhan. Emerg Microbe Infect 2020; 9: $221-36$.

7. Wilder-Smith A, Chiew CJ, Lee VJ. Can we contain the COVID-19 outbreak with the same measures as for SARS? Lancet Infect Dis 2020; 20: e102-7.

8. Yan Y, Chang L, Wang L. Laboratory testing of SARS-CoV, MERSCoV, and SARS-CoV-2 (2019-nCoV): current status, challenges, and countermeasures. Rev Med Virol 2020; 30: e2106.

9. World Health Organization WHO. Laboratory Biosafety Manual. 3rd ed. Geneva: WHO, 2004

10. Standards Australia. Safety in Laboratories Part 3: Microbiological Safety and Containment. Sydney: Standards Australia, 2010. AS/NZS 22433-2010.

11. American Biological Safety Association. Risk group database. Cited Aug 2020. https://my.absa.org/Riskgroups

12. Public Health Agency of Canada. Pathogen safety data sheets and risk assesments. Cited Aug 2020. https://www.canada.ca/en/public-health/ services/laboratory-biosafety-biosecurity/pathogen-safety-data-sheetsrisk-assessment.html

13. Directive 2000/54/EC of the European parliament. Cited 18 Sep 2020. https://eur-lex.europa.eu/eli/dir/2000/54/oj

14. Chosewood L, Wilson D. Biosafety in Microbiological and Biomedical Laboratories. 5th ed. Washington, DC: US Department of Health and Human Services, 2009.

15. Rohde R. Novel coronavirus lab protocols and responses: next steps an introduction to coronavirus biology and genetics. 3 Feb 2020 cited Aug 2020. https://asm.org/Articles/2020/February/Next-Steps-forNovel-Coronavirus-Medical-Laborator

16. Lim PL, Kurup A, Gopalakrishna G, et al. Laboratory-acquired severe acute respiratory syndrome. $N$ Engl J Med 2004; 350: 1740-5.

17. Schröder I. COVID-19: a risk assessment perspective. J Chem Health Saf 2020; 27: 160-9.

18. Committee on Biological Agents (ABAS). Rationale for the provisional classification of the SARS-CoV-2 virus as a risk group 3 biological agent and recommendations for non-targeted activities (laboratory diagnostics) and targeted activities with SARS-CoV-2. 26 May 2020; cited Aug 2020. https://www.baua.de/DE/Aufgaben/ Geschaeftsfuehrung-von-Ausschuessen/ABAS/pdf/SARS-CoV-2-en. pdf?_blob=publicationFile \& $v=4$

19. Iannetta M, Di Caro A, Nicastri E, et al. Viral hemorrhagic fevers other than Ebola and Lassa. Infect Dis Clin North Am 2019; 33: 977-1002.

20. Cobo F. Viruses causing hemorrhagic fever. Safety laboratory procedures. Open Virol J 2016; 10: 1-9.

21. Khafaie MA, Rahim F. Cross-country comparison of case fatality rates of COVID-19/SARS-COV-2. Osong Public Health Res Perspect 2020; 11: $74-80$.

22. Yang J, Zheng Y, Gou X, et al. Prevalence of comorbidities and its effects in patients infected with SARS-CoV-2: a systematic review and meta-analysis. Int J Infect Dis 2020; 94: 91-5.

23. Oran DP, Topol EJ. Prevalence of asymptomatic SARS-CoV-2 infection: a narrative review. Ann Intern Med 2020; 173: 362-7. 
24. Australian Government Department of Health. Update on SARS-CoV-2 SSBA Newsl 2020; Aug: Issue 30.

25. Public Health Laboratory Network (PHLN). PHLN guidance on laboratory testing for SARS-CoV-2 (the virus that causes COVID-19). 14 Mar 2020; cited Aug 2020. https://www.health.gov.au/resources/ publications/phln-guidance-on-laboratory-testing-for-sars-cov-2-thevirus-that-causes-covid-19

26. Centers for Disease Control (CDC). Recognizing the biosafety levels. Cited Aug 2020. https://www.cdc.gov/training/QuickLearns/biosafety/ 